\title{
TRENDS OF CONSUMER PURCHASES VIA SOCIAL MEDIA ACCORDING TO THE STIMULUS-ORGANISM-RESPONSE (SOR) MODEL
}

\author{
Aija Vonoga \\ Mg.soc.sc., scientific assistant, Rezekne Academy of Technologies, Rezekne, Latvia, \\ aija.vonoga@rta.lv
}

\begin{abstract}
The theme of this paper is "Trends of Consumer Purchases via Social Media according to the Stimulus-Organism-Response (SOR) Model". Social media are an important platform for entrepreneurship development, and a lot of entrepreneurs are using social media for marketing and selling activities in order to increase sales and attract potential customers. The topicality of the research is based on economic development requirements. The aim of the research - to identify the situation and to develop proposals for entrepreneurs and managers in Latvia. The tasks of the research are the following: to develop a survey, to carry out theoretical research; to develop proposals. The research period was from March until June 2021. General scientific research methods were used in the research: the monographic and descriptive methods, the survey method, the comparative analysis method for studying the concept of SOR at social networking and future development possibilities. The survey conducted in the study showed the tendencies of Latvian consumers' purchases via social media. The study hypothesis confirmed that according to the Stimulus-OrganismResponse Model, advertising, opinion leaders, and user-generated content act as the stimulus (S) to evoke positive emotions (O), which later leads to impulse purchases $(R)$ for consumers.
\end{abstract}

Keywords: Company, Entrepreneurship, Management, Organism, Response, Social media, Stimulus.

JEL code: L26, M21

Received: 9 September 2021 Revised: 30September 2021 Accepted: 9 November 2021 Published: 10 December 2021

\section{Introduction}

Digital, mobile, and social media have become an indispensable part of everyday life for people all over the world. More than 4.5 billion people now use the Internet, while social media users have passed the 3.8 billion mark (Kemp, 2020). The growth of social media has completely revamped the way people interact, communicate and engage. These platforms play a key role in facilitating greater outreach and influence (Anuja et al., 2019).

Social media are used not only for everyday communication but also for creating a business environment. Companies use social media to carry out marketing campaigns, find potential customers. Consumers can easily find the necessary shops, tourist sites, etc. via social media. Social platforms have become a vital driver of business. 
The role of Internet sources has steadily increased in recent years, and it is one reason that differentiates COVID-19 from previous pandemics (AbdAlrazaq et al., 2020; Farooq et al., 2020). Exposure to online information sources refers to the number of online sources through which people receive information. Making sense of the vast amount of information from multiple sources is not straightforward, as conflicting, unclear, and even fake news circulate constantly on the Internet (Laato et al., 2020; Talwar et al., 2019, 2020). During unprecedented and unusual events, such as the COVID-19 pandemic, the novelty of the situation does not allow relying extensively on existing cognitive knowledge structures, which can increase the amount of circulating fake news (Ahmed et al., 2020; Laato et al., 2020).

The research hypothesis - according to the Stimulus-OrganismResponse Model, advertising, opinion leaders, and user-generated content act as the stimulus (S) to evoke positive emotions $(0)$, which later leads to impulse purchases (R) for consumers.

The aim of the research - to identify the situation and to develop proposals for entrepreneurs and managers in Latvia. The tasks of the research are the following: to develop a survey, to carry out theoretical research; to develop proposals.

General scientific research methods were used in the research: the monographic and descriptive methods, the survey method, the comparative analysis method for studying the concept of SOR at social networking and future development possibilities.

\section{Social networks}

Borgatti and Halgin (Borgatti, Halgin., 2011) observed that the term 'social network' has developed to mean anything from a private club to a website and can therefore lead to some confusion. They describe a network as "a set of actors or nodes along with a set of ties of a specified type...that link them." These ties connect via shared points to link nodes that are not directly linked themselves, the nodes being individuals, or actors in the network. Unlike groups, networks do not have natural boundaries, and they do not need to be connected internally. These disconnected parts of the network can become connected over time, meaning networks are fluid and ever changing (Stone, 2018).

Social media use has become an indispensable part of knowledge work. Employees posting work-related content on social media are considered credible sources of information and have significant importance for how stakeholders, such as potential customers and future employees, perceive the organization. Therefore, employees' ability to communicate about their work on social media has become a competitive advantage both for 
individual employees and for their organizations, especially in the professional service sector. Hence, understanding the role of employees' ability to use these social media professionally is crucial for understanding the communicative behaviours of contemporary knowledge workers (Pekkala et al., 2021). Social media is used professionally by employees to develop the external image of their company, promote sales and overall growth. The role of social media is very important in today's business._The most popular social media in Latvia at the moment are Facebook, Instagram, Draugiem.lv, Twitter, TikTok and others.

At its most basic, Instagram is a social networking app which allows its users to share pictures and videos with their friends. The app can be downloaded for free from the usual app stores and takes pride of place on many young person smartphones. The company was founded by Kevin Systrom and Mike Krieger, both Stanford University graduates, in 2010 and now has around 200 million users. Facebook, the social networking giant, acquired the company in 2012. While its basic premise is the sharing of pictures, the site's popularity comes from its picture-editing functionality. Once a user snaps a picture, Instagram filters - of which there are dozens can transform images in a manner reminiscent of old-fashioned Polaroid prints. The app not only allows for the creation of personal profiles but also can be connected to existing social networking profiles such as Facebook and Twitter, meaning users can share their pictures across platforms (Webwise.ie, 2020). By publishing images on the video site Instagram, the company promotes and shows its product to a potential buyer in detail, as well as emotionally impresses the potential buyer by offering advantageous offers - promotions, discounts, coupons, etc.

$90 \%$ of Instagram users follow a business. People are not just interacting with their friends and family on Instagram. Almost everyone who uses the app follows at least one brand. $36.2 \%$ of B2B decision makers use Instagram to research new products or services. That ranks it ahead of LinkedIn but behind YouTube, Facebook, and WhatsApp. It's a clear indication that Instagram is an important business tool, whether you're marketing to consumers or other organizations (Newberry, 2021).

Facebook is a social networking site that makes it easy for you to connect and share with family and friends online. Originally designed for college students, Facebook was created in 2004 by Mark Zuckerberg while he was enrolled at Harvard University. By 2006, anyone over the age of 13 with a valid email address could join Facebook. Today, Facebook is the world's largest social network, with more than 1 billion users worldwide (GCFGlobal.org, 2021). Facebook is the largest social networking platform in the world, which is why most businesses can be found on it. Nowadays, if a consumer wants to buy a particular product or service, they first look for 
information on the Facebook social networking platform, because if the company is not registered on that platform, it is likely to be inactive or closed.

\section{Influencer marketing}

Influencer marketing is on the rise, which is made apparent by the recently released figures indicating that the value of this specific market more than doubled between 2019 and 2021, growing from 6.5 billion to 13.8 billion U.S. dollars in the three years alone (Statista.com, 2021).

Influencer marketing is a fast-growing trend that is influencing business development on social networking platforms.

The survey found that Facebook (86 percent) and Instagram (84 percent) were the overall top social media channels for influencer marketing, with Instagram ranking as the single most important channel (36 percent) followed by Facebook at 20 percent. "It's clear that the popularity of influencer marketing has increased among marketers in recent years, largely due to the growth and evolution of social media," said ANA CEO Bob Liodice. "We've found that a growing number of marketers are turning to influencers to help them combat ad blocking, leverage creative content in an authentic way, drive engagement, and reach millennial and gen $\mathrm{Z}$ audiences who avidly follow and genuinely trust social media celebrities." The study pointed out that brands hire influencers with audience followings ranging from as few as 50 followers to over 100,000. For the purposes of the report, influencers were defined as micro (50 to 25,000 followers), mid-level $(25,001$ to 100,000), and macro (over 100,000). Influencer Marketing Objectives: the great majority of respondents (86 percent) stated that general brand awareness was an objective for engaging in influencer marketing. More than two-thirds (69 percent) said they utilize influencer marketing for content creation and distribution, and over half conduct influencer marketing to improve brand perception and drive purchase (56 percent and 51 percent, respectively) (Wolfe, 2018).

A number of studies have been conducted on the professional activities of influencer leaders on social networking platforms, which have found that influencer leaders' advertising services are used to improve brand awareness and encourage the purchase of goods or services.

Influencers, or opinion leaders known in the society or in a group of society, are a novelty of Latvian marketing in the last couple of years, which is used by not only one brand, and they have been known in the world for a long time. Influencer marketing is a type of marketing that focuses on specific opinion leaders, using their visibility as a marketing tool. Most often, influencer marketing works directly in the environment of social media, where they are followed by different target groups. Social media influencers 
are people known in an industry or niche who are active in various social media platforms and have gathered a significant number of followers. Given the size of the global audience, they can be divided into 3 categories: micro (5 - 100 thousand followers), mid or medium (100 thousand - 1 million followers) and macro influencers (more than 1 million followers). Anyone can become an opinion leader, the main rule is to find your industry and attract an audience. One of the most grateful platforms is Instagram (also YouTube, if the video format is close) where you can quickly gather a large number of followers. The next step is to create content that is original, interesting and engaging to the audience. It is often the case that the brand itself addresses the influencers so that they include information about the product or service in their social network entries in return for either remuneration or the product itself. It all depends on the purpose of the cooperation and the agreement. It is clear that it is useful to use the views of recognizable people in your marketing strategy. Is it a short-term or longterm investment? $60-70 \%$ of brands in the world use influencers to promote sales results, but only $5 \%$ of them incorporate them into a long-term marketing strategy. Of course, building a long-term relationship with a particular person is not easy, but research shows that it promotes the loyalty of the target audience and strengthens the basic customer base. One of the ways to attract well-known people is to create a brand newsletter programme - to choose a person or people as brand newsletters who participate in marketing activities or become the face of advertising (Topmedia.lv, 2021).

There are many opinion leaders on Latvian social media platforms, who also provide their advertising services to promote specific goods or services.

Social media influencers have become important opinion leaders in certain audiences, so the question of the reliability, competence and openness of the information they offer and the number of followers about sponsored content is becoming more and more important. Following the international Golin global data-based approach, Accelerators of Relevance together with cooperation partners HypeAuditor and Norstat, GOLIN Riga has already created the third Latvian Golin Accelerators of Relevance Influencer Index 2021 (GolinRiga, 2021).

\section{Stimulus-organism-response (S-O-R) model}

The Stimulus-organism-response (S-O-R) model was proposed by (Woodworth, 1929) as an extension to the classic theory of the stimulusresponse model suggested by (Pavlov, 1927). The S-O-R model is comprised of three constructs i.e. stimulus, organism, and response, which decide the behavioural outcome of an event. (Skinner, 1935) described the notion of stimulus and response as "parts of behaviour and environment" and sudden 
changes in the environment can influence the psychological and emotional stability of an individual which further drives the behavioural changes (Donovan, Rossiter, 1982). The stimulus is the outside forces that affect the psychological state of an individual (Jacoby, 2002; Peng, Kim, 2014; Young, 2016) and (Eroglu et al., 2001) defined the stimulus as "the influence that arouses the individual".

The intervening processes and structures consist of perceptual, physiological, feeling, and thinking activities". (Fu et al., 2020) defined the organism as "internal processes and outcomes of the stimulus, usually mediating the relationship between a stimulus and a response".

The response in the model refers to the final behavioural outcome of an individual that may be positive or negative (Donovan, Rossiter, 1982; Spence, 1950).

There is a significant difference in the stimulus, organism and response between these elements. The greater the stimulus, the greater the organism response to these stimuli.

The framework is based on work by Mehrabian and Russell (Mehrabian, Russell, 1974) who conceptualized behaviour as occurring in an environment, which consists of stimuli. The stimuli affect the organism, more specifically, consumers' cognitive and affective processes, which then leads to a behavioural response. An individual's previous knowledge, thinking skills, and self-efficacy have moderating effects on the behavioural response (Attiq et al., 2017). Although the environment ultimately pushes organisms toward certain reactions, individual and group characteristics may act as an opposing or amplifying force (Laato et al., 2020).

\section{Research and results}

This paper investigates which types of social networking tools are most effective in relation to consumer impulse buying behaviour in the field of trade in the Latvian context. The study was conducted according to the Stimulus-Organism-Response model in the context of social media. Social media are very influential in encouraging the purchase of impulses among consumers, but this is not the case for all respondents.

A questionnaire is a method of gathering initial information, which envisages asking the research group oral or written questions that contain the research problem on an empirical level, as well as statistical processing of the obtained answers. The quality of the information obtained during the survey largely depends on the quality of the development and application of the survey as a method of collecting information. Nowadays, survey methods are used to study issues where the medium is a person (Kristapsone, 2008). 
The survey contained 12 questions about consumer shopping trends on social media. The aim of the survey was to investigate a correlation between the elements - the Stimulus, Organism and Response. 84 respondents from various Latvian cities participated in the survey. By gender, $80 \%$ were women and $20 \%$ men. The average age was 34 years. The survey was divided into three categories of questions according to the SOR model.

The first question of the survey found out via which social media customers commonly made the purchases. The majority $-42.9 \%$ answered that Facebook, 32.1\% Instagram, 25\% answered that they use others regular stores, online stores- Asos, Member, Zara, AliExpress, Sinsay, Crop, 220 , Coconut, Amazon. The study author concludes that the most influential social networking platform was Facebook.

\section{Stimulus}

After creating the portrait of the respondent, questions were asked based on the Stimulus concept, why the buyer made purchases.

When you are shopping in online stores, do you pay attention to the appearance of the company's profile - logo, colour scheme, style? Yes, it is important to me (42.9\%). No, I will not pay attention $(10.7 \%)$. The majority answered that it was neutral (46.4\%). From this it can be concluded that the majority of customers do not notice and are neutral towards the appearance of the profile of a company posted on social media - the logo, colour scheme, style, but this does not mean that customers are not affected.

The second question - When you are shopping in online stores, do you pay attention to the layout of the company's profile, website? Yes, it is important to me (71.4\%). No, I do not pay attention (17.9\%). Neutral $(10.7 \%)$. The vast majority of the respondents answered that layout was important for comfortable and convenient shopping.

To the next question - What motivates you to make a purchase? - various answers were given: discounts $28 \%$; promotions $26.7 \%$; added value $10.7 \%$; high quality photos $14.7 \%$; good description $8 \%$; professional salespeople $10.7 \%$; social campaigns $1.3 \%$. From the answers provided, the author concludes that the biggest incentive to make purchases was promotions and discounts, both marketing tools are the most effective.

When you are shopping in online stores, do you pay attention to the company's staff - employees who sell, advertise goods? Yes, for me it is a significant (32.1\%); No, for me it is not significant (25\%); Neutral (42.9\%). The author of the paper concludes that customers are neutral and do not pay attention to the company's staff - employees who sell, advertise goods.

To the question - Has the choice of your purchases been influenced by the content creators or opinion leaders (influencers) - advertisements, 
reviews? Various answers were given - Yes, I trust to the opinion leaders (52.1\%); No, I am not affected (30\%); Neutral (17.9\%). The author concludes that the content created by opinion leaders (influencers) - advertisements, feedback - has influenced the purchase made by customers.

\section{Organism}

The second group of questions in the survey concerns the Organism response to a Stimulus.

To the question - Can you fully evaluate the product when you are shopping in online stores? Is there enough information on the Internet site? The following answers were given: Yes, I can always evaluate it (21.4\%). No, I cannot evaluate it (64.3\%). Neutral (14.3\%). The author of the paper concludes that customers cannot evaluate the completeness of the product, often there is not enough information and pictures about the product in online stores.

The next question was about experience - What is your experience when shopping in online stores that are available on social media? Positive (64.3\%). Negative (0\%). I have bought products rarely (35.7\%). Overall, the attitude and experience were very positive towards online shopping, which is available on social networking platforms.

The respondents answered the following questions about emotions: Have you made purchases based on emotions, mood? Yes, always (21.4\%). No, never $(21.4 \%)$. I have not thought about it (50\%). Sometimes $(7.1 \%)$. The author of the paper concludes that most of the customers did not think or made purchases based on their emotions and mood.

What are your emotions when receiving a purchase? Always positive (67.9\%). Miscellaneous (32.1\%). More often negative (0\%). A large majority of the respondents answered that emotions were positive when they were receiving a product purchased in online stores.

\section{Response}

The third group of questions studied the Response impact to the Organism.

To the question - When receiving the purchase, does the product correspond to what you had imagined or was completely different? The following answers were given: Yes, it always corresponds (25\%). Sometimes $(64.3 \%)$. No, not always (10.7\%). The author concludes that the expectations of the respondents and the reality were different, the purchased product corresponded only sometimes, there were situations where the product was received completely different. 
To the question - Did the new purchases improve your behaviour and self-confidence? The following answers were given - Yes, definitely (60.7\%); $39.3 \%$ have not thought about it. The majority of the respondents answered that new purchases improved their self-confidence and behaviour, and the author concludes that purchases in social media online stores have a positive tendency to respond.

The study used the Stimulus-Organism-Response Model and, summarizing the research data, has concluded that advertising, opinion leaders and user-generated content act as the stimulus (S) to evoke the organism emotions (0), which later leads to impulse purchases (R) for consumers. The hypothesis of the present research was confirmed by the research results.

\section{Conclusions and Proposals}

The author of the paper has concluded - the most influential social networking platform in Latvia is Facebook, and with the help of this platform consumers most often make choices and purchases. The most customers do not notice and are neutral towards the appearance of a company profile posted on social media - the logo, colour scheme, style, but this does not mean that customers are not affected. The layout of the store is important for customers to make comfortable and convenient shopping. The major incentive to make purchases is promotions and discounts, both marketing tools make the most effective impact to the organism and elicits a response. The customers are neutral and do not pay attention to the company's staff employees who sell, advertise goods. The content created by opinion leaders (influencers) - advertisements, reviews have influenced customers to make purchases. When customers are making purchases in social media online stores, they cannot fully evaluate the product, often the online store websites do not have enough information, a description and an image about the particular product.

In general, the attitude and experience are very positive towards online shopping, which is available on social networking platforms. Most of the customers have not thought about whether they have made purchases based on their emotion and mood. For a large majority of the respondents, emotions were positive when receiving a product purchased in online stores. The respondents' expectations about the product and reality were different, the product purchased corresponded only sometimes, there were often situations where the product was received completely different. New purchases improve customers' self-confidence and behaviour, from which the author concludes that purchases in social media online stores have a 
positive response trend. Social platforms have become a vital driver of business.

Entrepreneurs should register social network user accounts and actively use them, because it is an effective platform for attracting customers. Entrepreneurs should use influencer services, because it directly reaches and influences the consumers - the potential customers.

\section{References}

1. Abd-Alrazaq, A., Dari Alhuwail, D., Househ, M., Hamdi, M., Shah, Z. (2020). Top concerns of Tweeters during the COVID-19 pandemic: infoveillance study. Journal of Medical Internet Research, 22 (4) (2020), doi:10.2196/19016

2. Ahmed, W., Vidal-Alaball, J., Downing, J., Seguí, F.L. (2020). Dangerous messages or satire? Analysing the conspiracy theory linking 5G to COVID-19 through social network analysis. Journal of Medical Internet Research, 22(5), doi:10.2196/19458

3. Anuja, A., Shivam, B., Chandrashekhar, K., Reema, A., Yogesh, D. (2019). Measuring social media influencer index- insights from facebook, Twitter and Instagram. Lournal of Retailing and Consumer Services, 49, 86-101, https://doi.org/10.1016/j.jretconser.2019.03.012

4. Attiq, S., Rasool, H., Iqbal, S. (2017). The impact of supportive work environment, trust, and self-efficacy on organizational learning and its effectiveness: a stimulusorganism response approach. Business \& Economic Review, 9(2), 73-100, Retrieved from https://imsciences.edu.pk/files/journals/2017-vol-2/New\%204.pdf

5. Borgatti, S. P., Halgin, D. S. (2011). On Network Theory. Organization Science, 22, (5), 1168-1181.

6. Donovan, R., Rossiter, J. (1982). Store atmosphere: An environmental psychology approach. Journal of Retailing, 58(1), 34-57.

7. Eroglu, S.A., Machleit, K.A., and Davis, L.M. (2001). Atmospheric qualities of online retailing. Journal of Business Research, 54(2), 177184, https://doi.org/10.1016/S0148-2963(99)00087-9

8. Farooq, A., Laato, S., Islam, A.N. (2020). Impact of online information on selfisolation intention during the COVID-19 pandemic: cross-sectional study. Journal of Medical Internet Research, 22 (5), doi:10.2196/19128

9. $\mathrm{Fu}, \mathrm{S}$. , Chen, X., Zheng, H. (2021). Exploring an adverse impact of smartphone overuse on academic performance via health issues: A stimulus-organismresponse perspective. Behaviour \& Information Technology Journal, 40(7), 1-13, https://doi.org/10.1080/0144929X.2020.1716848

10. Gcfglobal.org (2021). What is Facebook? Retrieved from https://edu.gcfglobal.org/en/facebook101/what-is-facebook/1/

11. GolinRiga (2021). Influencer. Retrieved from http://www.influenceri.lv/mikroinfluenceri/

12. Jacoby, J. (2002). Stimulus-organism-response reconsidered: An evolutionary step in modeling (consumer) behavior. Journal of Consumer Psychology, 12 (1), 5157, https://doi.org/10.1207/S15327663JCP1201_05

13. Kemp, S. (2020). Digital in 2020: New decade, new milestones. Special report. Retrieved from https://wearesocial.com/blog/2020/01/digital-2020/ 
14. Kristapsone, S. (2008). Scientific research in the study process. Riga: School of Business Administration Turiba, 352 lpp.

15. Laato, S., Islam, A.K.M.N., Farooq, A., Dhir, A. (2020). Unusual purchasing behavior during the early stages of the COVID-19 pandemic: The stimulus-organismresponse approach. Lournal of Retailing and Consumer Services, 57, 102224, https://doi.org/10.1016/i.jretconser.2020.102224

16. Mehrabian, A., Russell, J.A. (1974). An Approach to Environmental Psychology. eBook. Cambridge, MA, US: The MIT Press.

17. Newberry, C. (2021). 44 Instagram Stats That Matter to Marketers in 2021. Retrieved from https://blog.hootsuite.com/instagramstatistics/\#Instagram business statistics

18. Pavlov, I.P. (1927). Conditioned reflexes: An investigation of the physiological activity of the cerebral cortex. Translated by GV Anrep (1st ed.), Oxford University Press.

19. Pekkala, K., van Zoonen, W. (2021). Work-Related Social Media Use : The Mediating Role of Social Media Communication Self-Efficacy. European Management Journal, In Press. https://doi.org/10.1016/j.emj.2021.03.004

20. Peng, C., Kim, Y.G. (2014). Application of the stimuli-organism-response (S-O-R) framework to online shopping behavior. Journal of Internet Commerce, 13 (3-4), 159-176, https://doi.org/10.1080/15332861.2014.944437

21. Skinner, B.F. (1935). The Generic Nature of the Concepts of Stimulus and Response. The Journal of General Psychology,12(1), 40-65,_Retrieved from: https://www.tandfonline.com/doi/abs/10.1080/00221309.1935.9920087

22. Spence, K.W. (1950). Cognitive versus stimulus-response theories of learning. Psychological Review, 57(3), 159-172, https://doi.org/10.1037/h0058250

23. Statista.com (2021). Influencer marketing market size worldwide from 2016 to 2021. Retrieved from https://www.statista.com/statistics/1092819/global-influencermarket-size/\#statisticContainer

24. Stone, T. (2018). Social Network Theory - a literature review for understanding innovation programs. Retrieved from https://medium.com/swlh/social-networktheory-a-literature-review-for-understanding-innovation-programs-7f1c214e9a77

25. Talwar, S., Dhir, A., Kaur, P., Zafar, N., Alrasheedy, M. (2019). Why do people share fake news? Associations between the dark side of social media use and fake news sharing behavior. Journal of retailing and consumer services. 51, 72-82, https://doi.org/10.1016/j.jretconser.2019.05.026

26. Topmedia.lv (2021). Influencers and marketing. Retrieved from https://www.topmedia.lv/post/influenceri-un-m\%C4\%81rketings

27. Webwise.ie (2020). Explained: What is Instagram? Retrieved from https://www.webwise.ie/parents/explained-image-sharing-app-instagram/

28. Wolfe, J. (2018). Advertisers Love Influencer. Marketing: ANA Study. Press Releases. Retrieved from https://www.ana.net/content/show/id/48437

29. Woodworth, R. (1929). 2nd ed. Psychology. (revised edition) eBook. New York, H.Holt and company.

30. Young, G. (2016). Stimulus-organism-response model: SORing to new heights. Unifying causality and psychology, Springer International Publishing, 699717, https://doi.org/10.1007/978-3-319-24094-7 28 